\title{
Factors affecting exclusive breastfeeding (EBF) among working mothers in Udupi taluk, Karnataka
}

\author{
Swastika Chhetri ${ }^{\mathrm{a}}$, Arathi P. Rao ${ }^{\mathrm{a}, *}$, Vasudeva Guddattu ${ }^{\mathrm{b}}$ \\ a Prasanna School of Public Health, Manipal Academy of Higher Education, Manipal, India \\ ${ }^{\mathrm{b}}$ Department of Statistics, Manipal Academy of Higher Education, Manipal, India
}

\section{A R T I C L E I N F O}

\section{Keywords:}

Working mothers

Exclusive breastfeeding

Maternity leave

\begin{abstract}
A B S T R A C T
Context: Employment of the mother is considered to be one of the most important barriers to exclusive breastfeeding (EBF).

Aim: To study the factors influencing EBF practices among working mothers in Udupi taluk.

Methods and material: A community-based cross-`sectional study was conducted among breastfeeding mothers employed in any form of occupation having an infant less than six months old $(\mathrm{n}=137)$. Interviewer administered structured questionnaire was used to collect data.

Statistical analysis used: Chi-square test was performed to find the association between different variables and EBF.

Results: The prevalence of EBF among working mothers was found to be $17.5 \%$ although $75 \%$ of them had adequate knowledge on EBF and its benefits. Around 52\% of the mothers did not receive any maternity leave benefits. Only $11 \%$ of mothers were allowed breaks in between working hours but none of the mothers were provided with crèches at their workplace. The commonest reason to discontinue EBF was early resumption of work after childbirth. Factors such as educational status of working mother and her husband, occupation of husband, place of delivery, sex of the newborn, frequency of breastfeeding per day, practice of expressing and storing breastmilk before leaving for work and breaks during working hours were found to be statistically significant with EBF practice.

Conclusions: These findings emphasize the need to guarantee the support to breastfeeding policies at workplace which in turn would motivate working mothers to continue EBF after resuming work.
\end{abstract}

\section{Introduction}

Mother's milk is considered to be the most effective means of infant nutrition. Provision of only breast milk to the infant for the first six months of life is highly recommended by experts as it is proved to be advantageous to both mother and the child. Today, only $38 \%$ of infants around the globe are exclusively breastfed for 6 months of life. ${ }^{1},{ }^{2}$ In India, according to NFHS-3 (National Family Health Survey 2005-06), 26 million babies are born annually out of which 20 million infants do not receive EBF. Also practice of EBF sharply declines from the first month with only $28 \%$ children receiving EBF by the end of six months. ${ }^{3}$ Almost $30 \%$ of newborns are still not exclusively breastfed in a high performing state like Karnataka (as per DLHS-4). ${ }^{4}$

Breast milk is a rich source of antibodies which provides immunity against bacteria and viruses to a newborn. Breastfeeding promotes special bonding between mother and baby, supports brain development and enhances the cognitive performance in the developmental stages of life. EBF for six months delays fertility, reduces the risk of type 2 diabetes, breast, uterine and ovarian cancer in the mother. ${ }^{5}$

Rapid industrialization, changes in lifestyle and other socio-cultural practices have been found to be the major factors influencing the breastfeeding practices across the nation. ${ }^{6}$ Although maternal employment plays a major role in the modern society there has not been enough evidences to support working mothers in promoting EBF policies at work. This may contribute to ineffective breastfeeding practices. Therefore, the aim of this study was to find out the factors affecting EBF practices among working mothers and their perspectives that would provide appropriate recommendations and evidences to highlight the need in promoting breastfeeding-friendly initiatives at workplace.

\footnotetext{
* Corresponding author.

E-mail address: arathimph@gmail.com (A.P. Rao).
} 


\section{Subjects and methods}

\subsection{Study design and duration}

This community based cross-sectional study was conducted in Udupi taluk, Karnataka between January to June 2016.

\subsection{Development and validation of questionnaire}

The study used interviewer administered structured questionnaire which was developed based on previous literature reviews. Final version of questionnaire with 50 items was prepared. The tools was translated into the local language. The tool was validated by peer review and reliability established from review by the subject experts. It comprised of four sections viz. socio-demographic profile, maternal and child health characteristics, knowledge on breastfeeding and patterns and practices of breastfeeding. During analysis occupation of mother and her husband were categorized into six different categories viz. professional, technical and managerial; clerical; sales; agricultural employee; services \& skilled and unskilled worker. This classification was derived from the NFHS-3 dataset. The section on knowledge on breastfeeding comprised of 6 questions. Each question had options in which one had to be ticked wherein the correct answer was marked ' 1 ' while the incorrect ones were marked ' 0 '. The scores for the level of knowledge on breastfeeding was then categorized into adequate and inadequate knowledge taking the 50th percentile as the reference level.

Data was analyzed using SPSS v 15.0 (SPSS Inc., Chicago, IL). Primary demographic tables were prepared where the categorical variables were expressed in frequency and percentages and the continuous variables in mean and standard deviation. Chi-square test was performed to find out the association between influencing variables and exclusive breastfeeding. The $\mathrm{P}<0.05$ was considered to be statistically significant.

\subsection{Study subjects and data collection method}

The study population included breastfeeding mothers having an infant less than six months old employed in any form of work. Mothers who were seriously ill and hospitalized were excluded from the study. The sample size was calculated based on prevalence of EBF in Udupi district which was $67.4 \% .{ }^{4}$ With the expected prevalence and an absolute allowable error of $8 \%$, at $95 \%$ confidence limits, the sample estimated was 131 working mothers. In the present study a total of 137 working mothers were interviewed.

Data was collected using simple random sampling technique. The participants were selected with the help of community health workers \{Accredited Social Health Activists (ASHA), Auxiliary Nurse Midwives (ANM) and Anganwadi Workers (AWWs)\}. Permission was obtained from CDPO Officer to visit anganwadi centres (AWCs) at Udupi taluk and also District Health Officer had permitted to visit 4 PHCs within Udupi Taluk i.e. Kapu, Brahmavar, Padubidri and Belman. Participants were tracked from the list available with the health workers for their respective area and then the samples fulfilling the inclusion criteria were selected randomly using lottery method.

A prior appointment was taken through phone calls from mothers who were not available at home during day and then the interview was scheduled at their homes according to the fixed date and time after they returned from work or on Sundays. Before taking the interview the mothers were explained about the study and its purpose. They were provided with the informed consent form. The interview proceeded with the help of a translator for the local language in case the mother was unable to understand Hindi/English. On an average 2 mothers were interviewed in a day depending on the schedule.

\subsection{Ethics}

Proposal was approved by the Institutional Ethics Committee (IEC) of Kasturba Medical College (KMC), Manipal University, Manipal, India.

\section{Results}

A total of 137 working mothers participated in the study. The mean age of these mothers was 28 years. Most of the participants were Hindus $(77.4 \%)$ by religion and majority (61\%) of them had higher education level. Similar distribution was seen among their husbands where their mean age was 34 years and only $54.7 \%$ had higher secondary and above education. Most of the mothers (43.8\%) and their husbands (23.4\%) were working as professionals, technicians and managers. Around $56.2 \%$ of the respondents belonged to nuclear family and nearly $45.3 \%$ of the participants' family earned more than Rs. 15,000 .

The prevalence of EBF among these mothers was very low. It was practiced by only $24(17.5 \%)$ out of 137 working mothers in accordance with WHO guidelines. Around 51\% of them attributed early return to work as a major barrier to EBF. Other reasons included inadequate breast-milk secretion, poor weight gain of the baby inspite of breast feeding and long distance from home to workplace. Health workers (doctors, nurses, ASHAs \& ANMs) were the major source of information on breastfeeding during antenatal and postnatal period to these mothers. Work related profile shows 136 (99.3\%) mothers were not provided with crèches at workplace.

The major challenges faced by the working breastfeeding mothers were to leave baby at home with their mother/mother in-law due to work pressure $(59.1 \%)$, no proper place to breastfeed at workplace (54\%) and busy schedule at work which was not conducive for breastfeeding (19.7\%). Other challenges included soiling of dress at workplace, leaving baby in the hands of caretaker, bringing baby along in the workplace and expressing milk that caused discomfort. Eighty seven $(63.5 \%)$ participants in the study provided some recommendations to improve exclusive breastfeeding practices for mothers who are working outside home. They expressed extension in maternity leave, changes in shift duty routine like exempting night shifts for breastfeeding mothers uptil 1 year after birth of the baby, provision of breastfeeding area and changing room at workplaces \& compulsory paid maternity leave for all working mothers.

Distribution of knowledge level showed that majority $(81 \%)$ of mothers knew the meaning of exclusive breastfeeding as feeding only breast milk and $46 \%$ of them knew the exact duration of EBF as per the WHO guidelines. Almost $94 \%$ of them said that colostrum was good for the baby. Nearly $74.5 \%$ of the mothers were aware that breastfeeding protects the infant against childhood illnesses like diarrhoea and pneumonia but only $48.2 \%$ of them were aware that EBF reduced the risk of cancers in mother.

Factors such as level of education of mother (P-value $=0.040$ ), level of education of husband (P-value $=0.028$ ) and occupation of husband ( $\mathrm{P}$-value $=0.040$ ) were statistically significant with EBF practice. The maternal, reproductive and child health characteristics revealed that mothers who visited the antenatal clinics more than 3 times during present pregnancy were able to practice exclusive breastfeeding (17.8\%) than those who had lesser than 3 visits. But this was not found to be statistically significant. Infants delivered at private hospitals were given exclusive breastfeeding (22.4\%) compared to those delivered at government institutions and this was found to be significantly associated ( $\mathrm{P}$-value $=0.016$ ). A positive aspect was found where sex of the newborn was found to be statistically significant ( $\mathrm{p}=0.046$ ) where baby girls were given exclusive breastfeeding (24.2\%) rather than baby boys.

The summarization of work related characteristics to EBF practice in the mothers have been shown in Table 1. Working mothers who got breaks in between work were able to practice exclusive breastfeeding 
Table 1

Distribution of participants according to socio-demographic characteristics $(\mathrm{n}=137)$.

\begin{tabular}{|c|c|c|}
\hline Variables & \multicolumn{2}{|c|}{ Frequency (\%) } \\
\hline Age of mother in years (Mean \pm SD) & \multicolumn{2}{|c|}{$27.64 \pm 4.84$} \\
\hline Age of the husband in years (Mean \pm SD) & \multicolumn{2}{|c|}{$34.48 \pm 5.27$} \\
\hline \multicolumn{3}{|l|}{ Religion } \\
\hline Hindu & 106 & $(77.4)$ \\
\hline Muslim & 4 & $(2.9)$ \\
\hline Christian & 27 & (19.7) \\
\hline \multicolumn{3}{|l|}{ Level of education of mother } \\
\hline No formal education & 11 & $(8.0)$ \\
\hline Primary & 12 & $(8.8)$ \\
\hline Secondary & 31 & $(22.6)$ \\
\hline Higher secondary and above & 83 & $(60.6)$ \\
\hline \multicolumn{3}{|l|}{ Level of education of husband } \\
\hline No formal education & 7 & $(5.1)$ \\
\hline Primary & 22 & $(16.1)$ \\
\hline Secondary & 33 & $(24.1)$ \\
\hline Higher secondary and above & 75 & $(54.7)$ \\
\hline \multicolumn{3}{|l|}{ Occupation of mother } \\
\hline Prof. Tech. Manag. & 60 & $(43.8)$ \\
\hline Clerical & 23 & (16.8) \\
\hline Sales & 18 & $(13.1)$ \\
\hline Agric. Employee & 2 & $(1.5)$ \\
\hline Service & 18 & (13.1) \\
\hline Skilled \& unskilled manual work & 16 & (11.7) \\
\hline \multicolumn{3}{|l|}{ Occupation of husband } \\
\hline Prof. Tech. Manag. & 32 & $(23.4)$ \\
\hline Clerical & 7 & $(5.1)$ \\
\hline Sales & 31 & $(22.6)$ \\
\hline Agric. Employee & 3 & $(2.2)$ \\
\hline Service & 40 & $(29.2)$ \\
\hline Skilled \& unskilled manual work & 24 & $(17.5)$ \\
\hline \multicolumn{3}{|l|}{ Type of family } \\
\hline Nuclear & 77 & $(56.2)$ \\
\hline Joint & 59 & $(43.1)$ \\
\hline Extended & 1 & $(0.7)$ \\
\hline \multicolumn{3}{|l|}{ Monthly family income (Rs.) } \\
\hline$<8000$ & 38 & $(27.7)$ \\
\hline $8001-15,000$ & 37 & $(27.0)$ \\
\hline$>15,000$ & 62 & $(45.3)$ \\
\hline
\end{tabular}

(53.3\%) than those who did not get breaks and this was found to be statistically significant (P-value $<0.001$ ).

$21(20.4 \%)$ out of 103 working mothers who had adequate knowledge exclusively breastfed their baby as depicted in Table 2. Nearly $33 \%$ of the mothers scheduled breastfeeding for 6-8 times in $24 \mathrm{~h}$ and $31.4 \%$ of the mothers' breastfed as often as the baby wanted the feed. This was found to be statistically significant $(\mathrm{P}$-value $=0.005$ ) where demand feeding was positively associated to exclusive breastfeeding (32.6\%) than scheduled feeding practices. Mothers who used to express and store the breast milk before leaving for their work were actually able to provide exclusive breastfeeding (33.3\%) to their baby. Also the practice of expressing and storing milk was found to be statistically significant with $\mathrm{EBF}$ practice $(\mathrm{P}$-value $=0.010)($ Table 3$)$. Table 4 shows the association between the level of knowledge and practice of EBF among the working mothers. Around $20 \%$ of the working mothers had adequate knowledge regarding various aspects of EBF in the present study.

\section{Discussion}

The prevalence of EBF in this study was found to be low at $17.5 \%$. This is not representative of the prevalence for the district as the present population consisted of working mothers only. ${ }^{7}$ But a study conducted by Gary $\mathrm{O}$ et.al showed the prevalence of exclusive breastfeeding among working mothers in Singapore was only $20 \%$ which is consistent
Table 2

Distribution of work related characteristics of mothers $(n=137)$.

\begin{tabular}{|c|c|c|}
\hline Attribute & \multicolumn{2}{|c|}{ Frequency (\%) } \\
\hline \multicolumn{3}{|c|}{ Distance from home to workplace (km) } \\
\hline$\leq 5$ & 76 & $(55.5)$ \\
\hline More than 5 & 61 & $(44.5)$ \\
\hline \multicolumn{3}{|c|}{ Type of employment } \\
\hline Part time & 19 & (13.9) \\
\hline Full time & 118 & $(86.1)$ \\
\hline \multicolumn{3}{|l|}{ Sector } \\
\hline Government & 5 & $(3.6)$ \\
\hline Private & 132 & $(96.4)$ \\
\hline \multicolumn{3}{|c|}{ Duration of maternity leave } \\
\hline Zero & 72 & $(52.6)$ \\
\hline 3 months & 60 & $(43.8)$ \\
\hline 6 months & 5 & $(3.6)$ \\
\hline \multicolumn{3}{|c|}{ Breastfeeding area at workplace } \\
\hline Yes & 1 & $(0.7)$ \\
\hline No & 136 & (99.3) \\
\hline \multicolumn{3}{|c|}{ Get breaks in between work to come home and breastfeed } \\
\hline Yes & 15 & (10.9) \\
\hline No & 122 & $(89.1)$ \\
\hline \multicolumn{3}{|c|}{ If yes, are the employers supportive? } \\
\hline Yes & 15 & (10.9) \\
\hline No & 0 & $(0.00)$ \\
\hline
\end{tabular}

Table 3

Association of work related characteristics with EBF practice among working mothers $(\mathrm{n}=137)$.

\begin{tabular}{|c|c|c|c|}
\hline Attribute & n (\%) & $\begin{array}{l}\text { EBF } \\
\text { Yes n (\%) }\end{array}$ & $\mathrm{p}$ value \\
\hline \multicolumn{4}{|c|}{ Distance from home to workplace (km) } \\
\hline$\leq 5$ & $76(55.5)$ & $13(17.1)$ & 0.887 \\
\hline More than 5 & $61(44.5)$ & $11(18.0)$ & \\
\hline \multicolumn{4}{|c|}{ Type of employment } \\
\hline Part time & 19 (13.9) & $4(21.1)$ & 0.745 \\
\hline Full time & $118(86.1)$ & $20(16.9)$ & \\
\hline \multicolumn{4}{|c|}{ Duration of maternity leave } \\
\hline Zero & $72(52.6)$ & $11(15.3)$ & 0.363 \\
\hline 3 months & $60(43.8)$ & $13(21.7)$ & \\
\hline 6 months & $5(3.6)$ & $0(0.0)$ & \\
\hline \multicolumn{4}{|c|}{ Get breaks in between work to come home and breastfeed } \\
\hline Yes & $15(10.9)$ & $8(53.3)$ & $<0.001^{*}$ \\
\hline No & $122(89.1)$ & $16(13.1)$ & \\
\hline
\end{tabular}

* Significant at p-value $<0.05$

to this study. ${ }^{8}$

All the mothers in the present study had institutional delivery and $71.5 \%$ of them delivered in a private hospital. This is consistent with the study by Rajesh et al from Mysuru. ${ }^{9}$ Majority of the mothers received information on EBF from community health workers. A similar finding was obtained in the study by Mekuria G et al in Ethiopia. ${ }^{10}$

In this study almost none $(99.3 \%)$ of the mothers were provided with crèches at workplace. Similar studies done in certain parts of India show consistent results where provision of a breastfeeding area is compromised at workplaces. This is similar to the findings from the study by Saxena V and Shwetha R. ${ }^{11,12}$ Working mothers who were able to obtain breaks during work were able to practice EBF. This is consistent with the findings in a global comparative analysis conducted by Jody et al where EBF rates increased with guaranteed breastfeeding breaks for atleast 6 months of the age of the child. ${ }^{13}$

As shown in Table 4 , around $20 \%$ of working mothers who had adequate knowledge breastfed their baby exclusively in Udupi taluk. Similar pattern was observed in a study conducted in Tanzania where only $58 \%$ out of $86 \%$ of mothers having adequate knowledge were 
Table 4

Breastfeeding practices and knowledge level among working mothers with EBF $(\mathrm{n}=137)$.

\begin{tabular}{|c|c|c|c|}
\hline Variable & n (\%) & $\begin{array}{l}\text { EBF } \\
\text { Yes n (\%) }\end{array}$ & $\mathrm{p}$ value \\
\hline \multicolumn{4}{|l|}{ Overall Knowledge } \\
\hline Inadequate & $34(24.8)$ & $3(8.8)$ & 0.124 \\
\hline Adequate & $103(75.2)$ & $21(20.4)$ & \\
\hline \multicolumn{4}{|l|}{ Initiation of breastfeeding } \\
\hline Within $1 \mathrm{~h}$ & $84(61.3)$ & $13(15.5)$ & 0.442 \\
\hline$>1$ to $24 \mathrm{~h}$ & $35(25.5)$ & $9(25.7)$ & \\
\hline$>24 \mathrm{~h}$ & 15 (10.9) & $2(13.3)$ & \\
\hline Do not remember & $3(2.2)$ & & \\
\hline \multicolumn{4}{|c|}{ Frequency of breastfeeding ( $24 \mathrm{~h})$} \\
\hline$<6$ times & $35(25.5)$ & $2(5.7)$ & $0.005^{*}$ \\
\hline 6 or more times & $59(43.1)$ & $8(13.6)$ & \\
\hline As often as the baby wants & $43(31.4)$ & $14(32.6)$ & \\
\hline \multicolumn{4}{|l|}{ Colostrum given } \\
\hline Yes & $136(99.3)$ & $24(17.6)$ & 0.644 \\
\hline No & $1(0.7)$ & $0(0.0)$ & \\
\hline \multicolumn{4}{|l|}{ Prelacteal feed given } \\
\hline Yes & 9 (13.9) & $2(10.5)$ & 0.388 \\
\hline No & $118(86.1)$ & $22(18.6)$ & \\
\hline \multicolumn{4}{|c|}{ Expresses and stores breast milk } \\
\hline Yes & $30(21.9)$ & $10(33.3)$ & $0.010^{*}$ \\
\hline No & $107(78.1)$ & $14(13.1)$ & \\
\hline
\end{tabular}

* Significant at p-value $<0.05$.

practicing EBF. ${ }^{14}$ The most common reason for working mothers to start supplementary feeding before six months of child's age was early return to work/business which is consistent with other studies where resumption of work was the major barrier to EBF among these mothers. ${ }^{8}{ }^{15-17}$

\section{Recommendations}

Provision of an exclusive place for breast feeding among working mothers along with a day care facility for the babies can enhance EBF practices. Nursing mothers should be exempted from night duties to promote EBF practice among the working mothers. Interventions for employers to enhance their awareness regarding EBF and breast feeding friendly practices at work places can increase the prevalence of EBF practices among the working mothers.

\section{Financial support \& sponsorship}

\section{Conflicts of interest}

There are no conflicts of interest.

\section{Acknowledgements}

The author acknowledges the guidance from Dr. Prakash Narayanan from Department of Public Health Manipal University, Manipal, India. A special thanks to all the working mothers for their time from the busy schedule for the interview.

\section{References}

1. Cai X, Wardlaw T, Brown DW. Global trends in exclusive breastfeeding. Int Breastfeeding J. 2012;7(12).

2. Lake A, Chen M. World breastfeeding week message. UNICEF; 2015.

3. International Institute for Population Sciences (IIPS) and Macro International. National family health survey (NFHS-3), 2005-2006: India. Vol. I. Mumbai: IIPS; 2007

4. International Institute for Population Sciences (IIPS). District level household and facility survey (DLHS-4), state fact sheet, 2012-13: Karnataka. 2014; 2014.

5. World Health Organization [Internet]; 2015 [cited 2015 Oct 5]. Available from: http://www.who.int/nutrition/topics/exclusive_breastfeeding/en/.

6. World Health Organization [Internet]; 2015 [cited 2015 Oct 6]. Available from: http://www.who.int/mediacentre/events/meetings/2015/world-breastfeedingweek/en/.

7. District level household and facility survey -4. District fact sheet. UDUPI; 2012.

8. Ong G, Yap M, Foo LL, Tai BC. Impact of working status on breastfeeding in Singapore: evidence from the national breastfeeding survey 2001. Eur J Public Health. 2005;15(4):424-430.

9. Rajesh J, Renuka M, Kulkarni P, Ashok NC. Perception and practices of mothers on breast feeding and its influence on childhood illness in rural Mysore. Int $J$ Recent Sci Res. 2014;5(1):285-288.

10. Mekuria G, Edris M. Exclusive breastfeeding and associated factors among mothers in Debre Markos, Northwest Ethiopia: a cross sectional study. Int Breastfeeding $J$ [Internet]. 2015;10(1):1-7.

11. Saxena V, Kumari R. Infant and young child feeding - knowledge and practices of ASHA workers of Doiwala block, Dehradun District. Indian J Community Heal [Internet]. 2014;26(1):68-75. Available from: http://www.iapsmupuk.org/journal/ index.php/IJCH/article/view/565/html_13.

12. Swetha R, Ravikumar J, Rao RN. Study of breastfeeding practices in coastal region of South India : a cross sectional study. Int J Contemp Paediatr. 2014;1(2):74-78.

13. Heymann J, Earle A. Breastfeeding policy : a globally comparative analysis. Bull World Health Organ. 2013(April):398-406.

14. Nkala T, Msuya S. Prevalence and predictors of exclusive breastfeeding among women in Kigoma region, Western Tanzania: a community based cross-sectional study. Int Breastfeed $J$ [Internet]. 2011;6(1):17. BioMed Central Ltd, Available from: http://www.internationalbreastfeedingjournal.com/content/6/1/17.

15. Danso J. Examining the practice of exclusive breastfeeding among professional working mothers in Kumasi metropolis of Ghana. Int J Nurs. 2014;1(1):11-24.

16. Foo LL, Quek SJS, Ng SA, Lim MT. Breastfeeding prevalence and practices among Singaporean Chinese, Malay and Indian mothers. Health Promotion International. 2005;20(3).

17. Murtagh L, Moulton AD. Working mothers, breastfeeding, and the law. Am J Public Health. 2011;101(2):217-223

Nil. 